\title{
A Fuzzy Logic Controller Approach for Controlling Heat Exchanger Temperature
}

\author{
Indah Soesanti $^{* 1}$, Ramadoni Syahputra ${ }^{2}$ \\ ${ }^{1}$ Department of Electrical Engineering and Information Technology, Faculty of Engineering, Universitas Gadjah Mada \\ Jl. Grafika 2, Kampus UGM, Yogyakarta, Indonesia \\ ${ }^{2}$ Department of Electrical Engineering, Universitas Muhammadiyah Yogyakarta \\ Jl. Lingkar Selatan, Tamantirto, Kasihan, Yogyakarta, Indonesia \\ *Corresponding author, e-mail: indahsoesanti@ugm.ac.id
}

\begin{abstract}
This paper presents a fuzzy logic controller approach for controlling heat exchanger temperature. Fuzzy logic controller is an artificial intelligence-based controller. The fuzzy logic controller has been widely used for control applications in the industrial world. One of the tools used in the industrial world that requires accurate control is the heat exchanger. A heat exchanger is a device used to process the mixing of liquids that have different temperatures. In this case, temperature control becomes very important. Fuzzy logic control is applied to the heat exchanger so that the mixed fluid has a constant temperature. Fuzzy logic control models in this study are combined with neural network techniques. The fuzzy logic controller model is simulated in Matlab software. The results showed that the fuzzy logic controller was able to stabilize the temperature of the heat exchanger well.
\end{abstract}

Keywords: Artificial Intelligence, Fuzzy Logic Controller, Heat Exchanger, Temperature Controller

\section{Introduction}

The application of artificial intelligence-based techniques in the control system has become an essential issue in the last two decades [1]-[2]. One technique based on artificial intelligence is widely used in the control system is a fuzzy logic techniques [3]. Fuzzy logic is a development of the primitive logic that only recognizes two states, namely "yes" or "no". With the fuzzy logic, it can recognize linguistic variables like rather large, large, very large, and so forth. Thus, the application of fuzzy logic will lead to a more adaptive system [4].

Controlling temperature is an essential process in the industry, such as light bulbs, the dairy industry, the pharmaceutical industry, incubators, and others [5]. During this time, the temperature control is still using the on-off switch manually. This research attempts to simulate the use of the neuro-fuzzy method, which is often also known by the method of the Adaptive Neuro-Fuzzy Inference System to control the temperature in the heat exchanger.

This study aims to learn the more in-depth method of neuro-fuzzy through networking concepts and adaptive inference systems fuzzy logic and create a software-simulated control of the temperature of the heat exchanger at the reactor clams using neuro-fuzzy, which developed in the software of Matlab-Simulink. The main contribution of this study is to the world of education and research community or another (industry, banking, and companies) that have high interest or interest, directly or indirectly. More concretely, the contribution is that by using the model to be made in this research, users can learn concepts and workings of Neuro-Fuzzy on intelligent systems, especially in the temperature control problem. Another contribution is that by overcoming the problem of temperature control heat exchanger in chemical reactors, the production process errors can be minimized to increase the productivity of industries, for example, the dairy 
industry, lights, and medicine.

The use of the method in the field of neuro-fuzzy control has been widely used. Control methods by applying the principles of fuzzy logic called FLC (fuzzy logic controller) [6]. How it works is similar to the control of an operator control, do not pay attention to the internal structure of the plant, just observe set-point error as the difference between the system outputs and change the control panel settings to minimize the error [7]. An FLC consists of defuzzification unit, fuzzy knowledge base, and fuzzy decision engine. Application of the neuralnetwork in solving various problems that are controlling the system of which have been successfully carried out in [8] which makes artificial neural network and fuzzy system to control of power flow, and in the [9] that suggests the artificial neural network with fuzzy approach for control of PSS.

The subsequent development of artificial intelligence systems are integrating the artificial neural network with fuzzy logic, which is known by Neuro Fuzzy [10]. Neuro Fuzzy has been accepted as a credible method and it is believed will continue to evolve in order to address the need for intelligent systems. Neuro Fuzzy is a fuzzy logic inference system that is implemented on a system of adaptive network [11].

An understanding of Neuro Fuzzy can be started from the basic principles of fuzzy logic system, neural networks artificial, the network neuro fuzzy, to the concept of Neuro Fuzzy and its application [12]. Neuro fuzzy system is a network of connections that realize the plural layered basic elements and functions of the control system or traditional fuzzy logic decision [13]. Because neuro fuzzy systems are universal approximator the neuro fuzzy control system is also universe approximator, because of its functions constitute an isomorphic with traditional fuzzy logic control system [14].

\section{Literature Study}

\section{II.1 Model of A Heat Exchanger}

The heat exchanger is a device used to perform the process of mixing a fluid having a different temperature [15]. Heat exchangers are widely applied in the dairy industry, medicine, and others. In this process, the expected is that the fluid that has been in a tank when mixed with new fluid input, then the total fluid in the tank, must quickly reach the desired temperature [16].
Fig. 1 shows the type of heat exchanger while the control scheme of a heat exchanger is shown in Fig. 2 . For cases where the available media hot liquid, such as water, the required heat exchanger with high efficiency [17]. To design a controller in the heat exchanger, the exact mathematical model of the process is determined. Most of the industrial system of non-linear in its application can be approximated as a first-order system with the added time delay (first order plus time delay, FOPTD) or models of the second-order plus time delay (secondorder plus time delay, SOPTD). The general shape and SOPTD FOPTD models can be expressed respectively in equation (1) and equation (2) as follows:

$$
\begin{aligned}
& G(s)=\frac{K_{p e^{-\tau} D S}}{\tau S+1} \\
& G(s)=\frac{K_{p e^{-\tau} D S}}{\left(\tau_{1} S+1\right)+\left(\tau_{2} S+1\right)}
\end{aligned}
$$

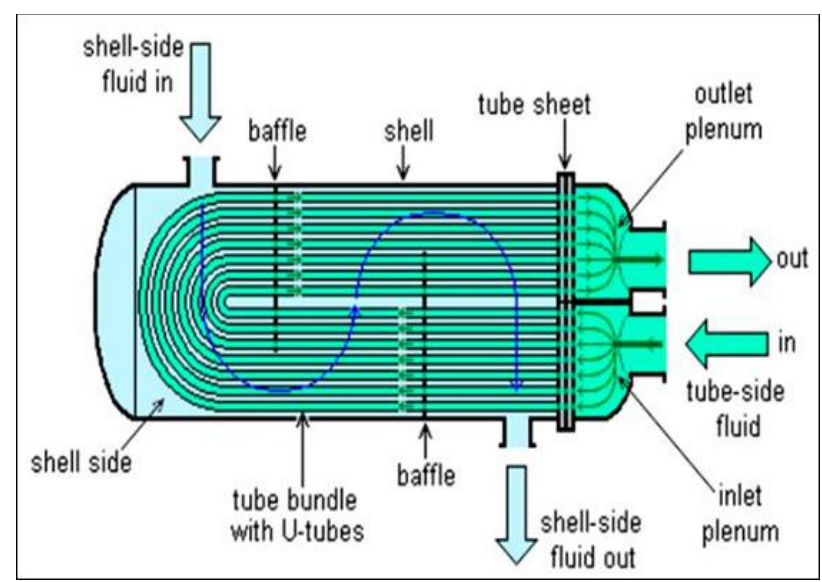

Fig. 1. Typical of a heat exchanger

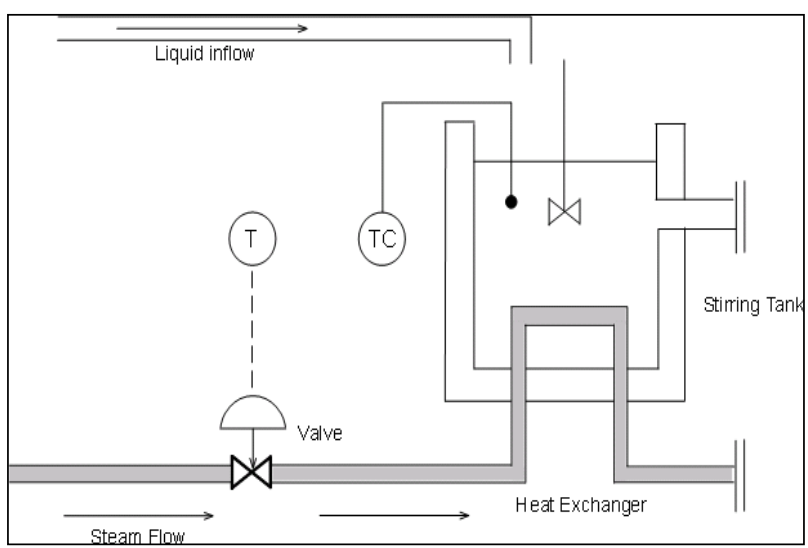

Fig. 2. Control scheme of a heat exchanger

\section{II.2 Neuro-Fuzzy Technique}

Neuro-Fuzzy technique has been becoming a popular method in many applications. A brief 
description of the principles of the Adaptive neurofuzzy inference system (ANFIS), which are referred to [3], is described in this section. The basic fundamental structure of the type of fuzzy inference system could be seen as a model that maps input characteristics to input membership functions. Then it maps input membership function to rules and rules to a set of output characteristics. Finally, it maps output characteristics to output membership functions and the output membership function to a single-valued output or a decision associated with the output.

The neuro-adaptive learning method works similarly to that of neural networks. Neuro-adaptive learning techniques provide a method for the fuzzy modeling procedure to learn information about a data set. It computes the membership function parameters that best allow the associated fuzzy inference system to track the given input/output data. A network-type structure similar to that of a neural network can be used to interpret the input/output map, so it maps inputs through input membership functions and associated parameters, and then through output membership functions and associated parameters to outputs. The parameters associated with the membership functions change through the learning process. The computation of these parameters (or their adjustment) is facilitated by a gradient vector. This gradient vector provides a measure of how well the fuzzy inference system is modeling the input/output data for a given set of parameters. When the gradient vector is obtained, any of several optimization routines can be applied in order to adjust the parameters to reduce some error measure (performance index). This error measure is usually defined by the sum of the squared difference between actual and desired outputs. ANFIS uses a combination of least squares estimation and backpropagation for membership function parameter estimation.

The suggested ANFIS has several properties:

1. The output of ANFIS is zero-th order Sugenotype system.

2. ANFIS has a single output, obtained using defuzzification of weighted average.

3. ANFIS has no rule for sharing. Different rules do not share for output membership function that has the same value.

4. ANFIS has unity weight for each rule.

Fig. 3 shows Sugeno's fuzzy logic model. Fig. 4 shows the ANFIS architecture, comprising by input layer, fuzzification layer, inference later, and defuzzification layer. The network can be visualized as consisting of inputs, with $\mathrm{N}$ neurons in the input layer and $\mathrm{F}$ input membership functions for each input, using $\mathrm{F}^{*} \mathrm{~N}$ neurons in the layer of fuzzification. In this case, there are FN rules with FN neurons in the inference, while there are defuzzification layers and one neuron in the output layer. It is assumed that the FIS under consideration has two inputs $\mathrm{x}$ and $\mathrm{y}$ and one output $\mathrm{z}$, as can be seen in Fig. 2. For a zero-order in Sugeno fuzzy model as used in this research, a common rule set with two fuzzy if-then rules is the following:

Rule 1: If $x$ is $A_{1}$ and $y$ is $B_{1}$, Then $f_{1}=r_{1}$

Rule 2: If $x$ is $A_{2}$ and $y$ is $B_{2}$, Then $f_{2}=r_{2}$

The output of the node $\mathrm{i}$-th in layer $\mathrm{n}$ is denoted as $\mathrm{O}_{\mathrm{n}, \mathrm{i}}$ :

Layer 1. Every node $\mathrm{i}$ in this layer is a square node with a node function:

$$
\begin{aligned}
O_{1}^{1}= & \mu \mathrm{Ai}(\mathrm{x}), \text { for } \mathrm{i}=1,2, \\
& \text { or, } \\
O_{1}^{1}= & \mu \mathrm{Bi}-2(\mathrm{y}), \text { for } \mathrm{i}=3,4
\end{aligned}
$$

where $\mathrm{x}$ is the input to node- $\mathrm{i}$, and $\mathrm{Ai}$ is the linguistic label (small, large, etc.) associated with this node function. In other words, $\mathrm{O}_{i}^{1}$ is the membership function of $\mathrm{Ai}$ and it specifies the degree to which the given $x$ satisfies the quantifier Ai. Usually $\mu \mathrm{Ai}(\mathrm{x})$ is chosen to be bell-shaped with maximum equal to 1 and minimum equal to 0 , such as the generalized bell function:

$$
\mu_{\mathrm{A}}(\mathrm{x})=\frac{1}{1+\left[\frac{\mathrm{x}-\mathrm{c}_{\mathrm{i}}}{\mathrm{a}_{\mathrm{i}}}\right]^{2 b_{\mathrm{i}}}}
$$

The parameters are referred to as premise parameters.

Layer 2. Every node in this layer is a circle node labelled $\Pi$ which multiplies the incoming signals and sends the product out. For instance,

$$
O_{1}^{2}=\text { wi }=\mu \mathrm{Ai}(\mathrm{x}) \mathrm{x} \mu \mathrm{B}(\mathrm{y}), \mathrm{i}=1,2 .
$$

Each node output represents the firing strength of a rule. (In fact, other T-norm operators that performs generalized AND can be used as the node function in this layer.)

Layer 3. Every node in this layer is a circle node labeled N. The i-th node calculates the ratio of the i- 
th rule's firing strength to the sum of all rules firing strengths:

$$
\mathrm{O}_{\mathrm{i}}^{3}=\overline{\mathrm{w}}=\frac{\mathrm{w}_{\mathrm{i}}}{\mathrm{w}_{1}+\mathrm{w}_{2}}, \quad \mathrm{i}=1,2 .
$$

For convenience, outputs of this layer will be called normalized firing strengths.

Layer 4. Every node $\mathrm{i}$ in this layer is a square node with a node function:

$$
\mathrm{O}_{\mathrm{i}}^{4}=\overline{\mathrm{w}}_{\mathrm{i}} \mathrm{f}_{\mathrm{i}}=\overline{\mathrm{w}}_{\mathrm{i}}\left(\mathrm{p}_{\mathrm{i}} \mathrm{x}+\mathrm{q}_{\mathrm{i}} \mathrm{y}+\mathrm{r}_{\mathrm{i}}\right)
$$

where $\overline{\mathrm{W}}_{\mathrm{i}}$ is the output of layer 3 , and $\{\mathrm{pi}$, qi, ri $\}$ is the parameter set. Parameters in this layer will be referred to as consequent parameters.

Layer 5. The single node in this layer is a circle node labeled $\Sigma$ that computes the overall output as the summation of all incoming signals, i.e.,

$$
\mathrm{O}_{\mathrm{i}}^{5}=\sum \overline{\mathrm{w}}_{\mathrm{i}} \mathrm{f}_{\mathrm{i}}
$$

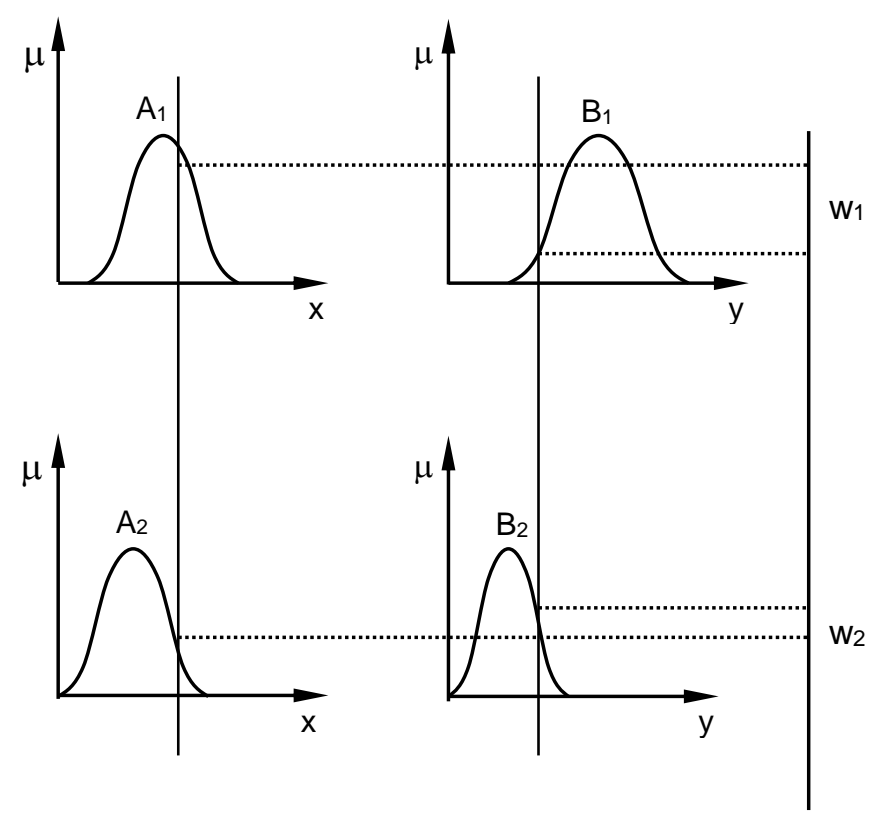

$$
\begin{gathered}
f_{1}=p_{1} x+q_{1} y+r_{1} \\
f_{2}=p_{2} x+q_{2} y+r_{2} \\
\downarrow \\
f=\frac{w_{1} f_{1}+w_{2} f_{2}}{w_{1}+w_{2}}
\end{gathered}
$$

Fig. 3. Sugeno's fuzzy logic model

$$
\begin{array}{lllll}
\text { Layer } 1 & \text { Layer } 2 & \text { Layer } 3 & \text { Layer } 4 & \text { Layer } 5
\end{array}
$$

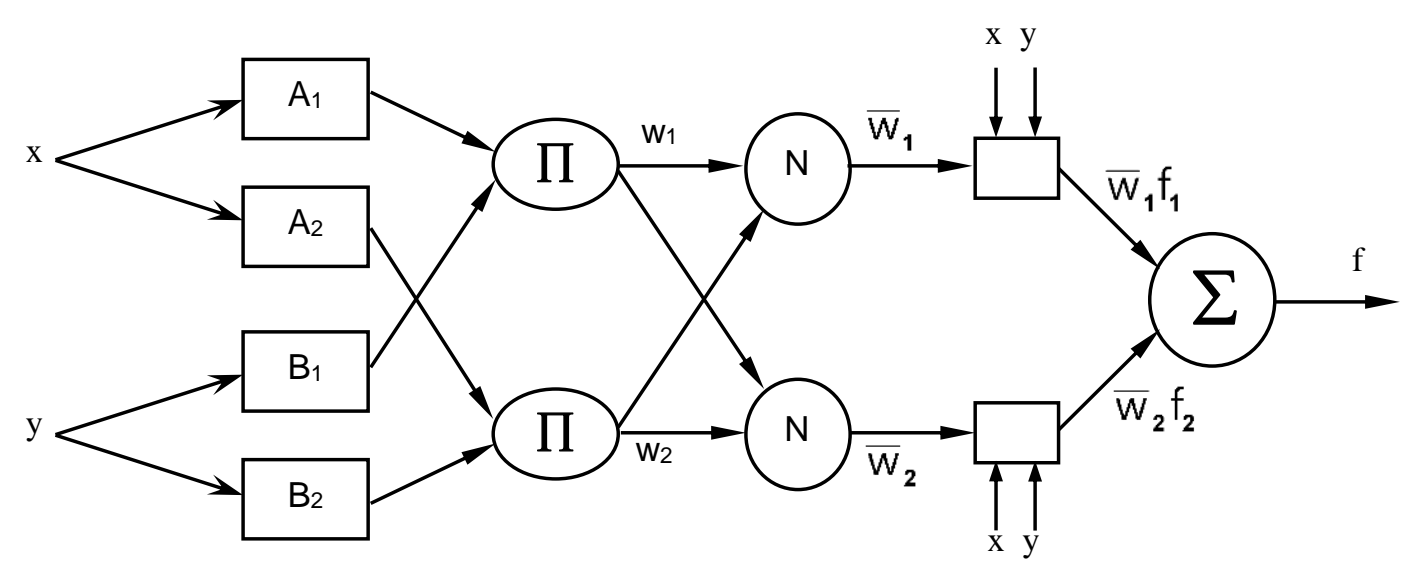

Fig. 4. The architecture of the 2-input and 1-output ANFIS 


\section{Results and Discussion}

\section{Methodology}

The design of a control model based on the neuro-fuzzy-based method to control the temperature of the heat exchanger as a process can be seen in Fig. 5. This study uses a closed-loop control scheme. The controller used is an adaptive neuro-fuzzy-based controller. As a comparison to see the performance of the control, it is tested using another type of control. Based on the control scheme in Fig. 5, we then implemented it in Matlab software, as shown in Fig. 6.

\section{IV.1 Model of Heat Exchanger Temperature Control}

In this research, the first step taken is to model the temperature control in a heat exchanger. This control model was created in Matlab software. The heat exchanger temperature control model in this study was made in Matlab software is shown in Fig. 7 .

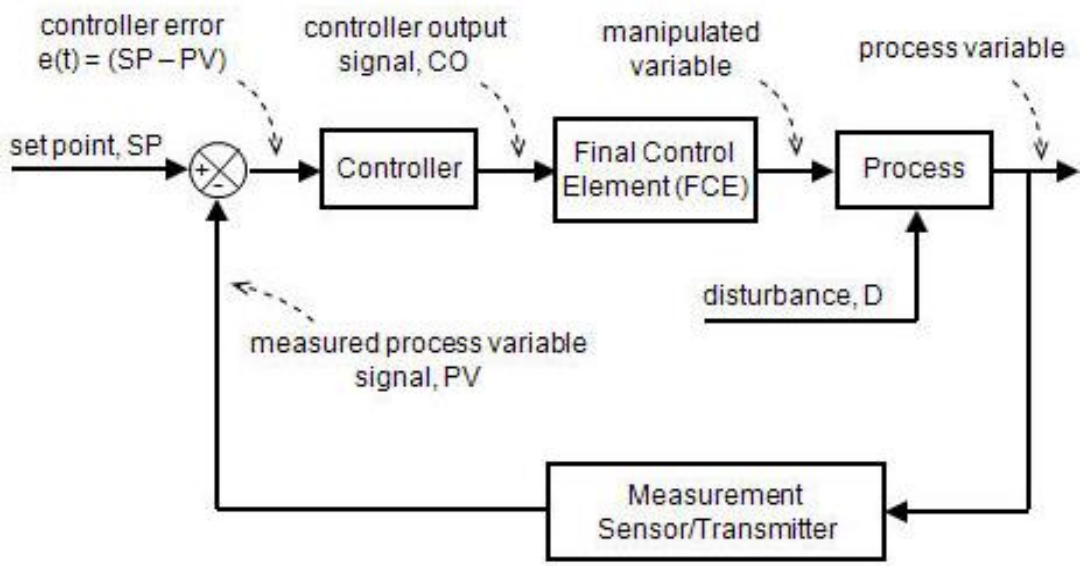

Fig. 5. Control scheme of a heat exchanger

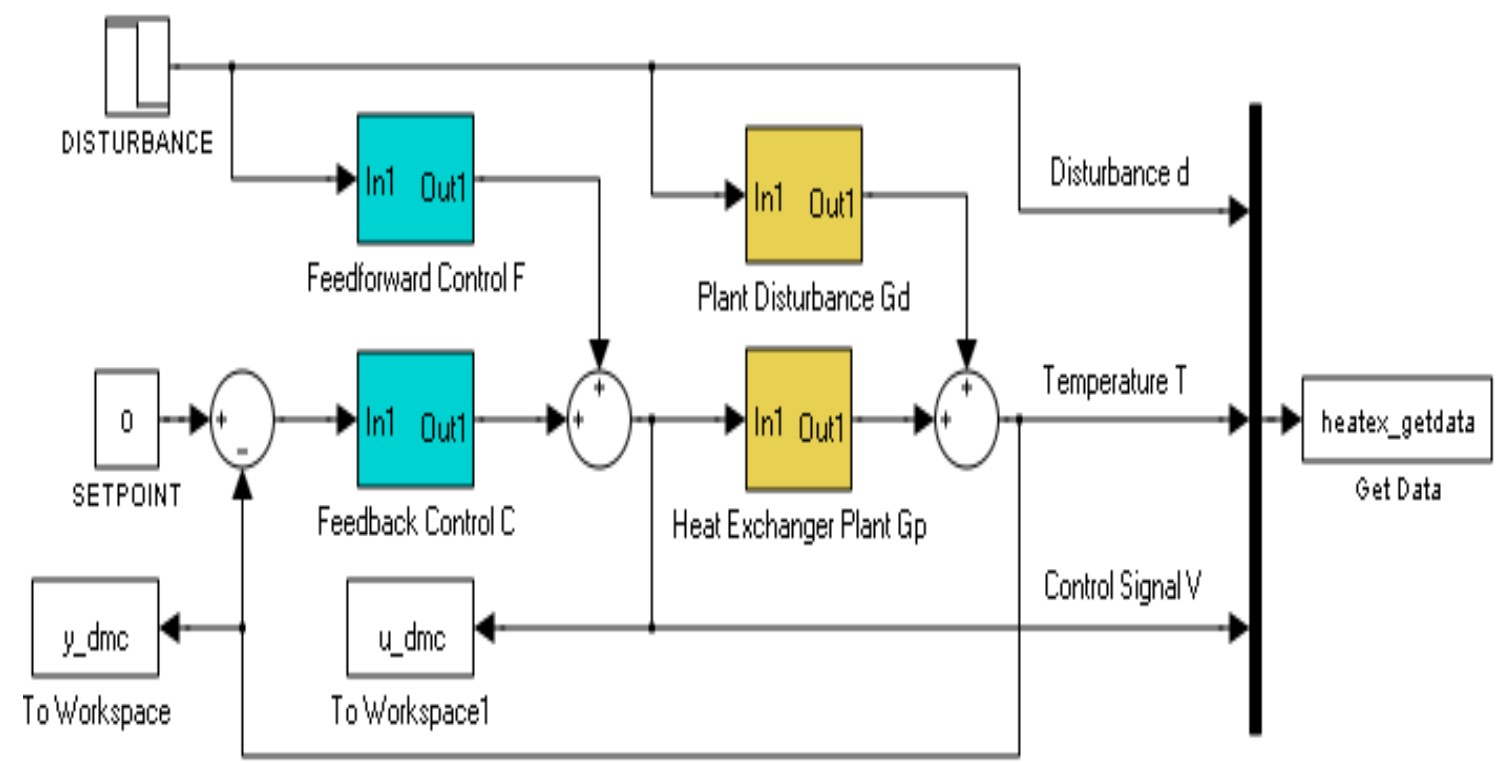

Fig. 6. Control scheme of a heat exchanger as a process in Matlab environment 


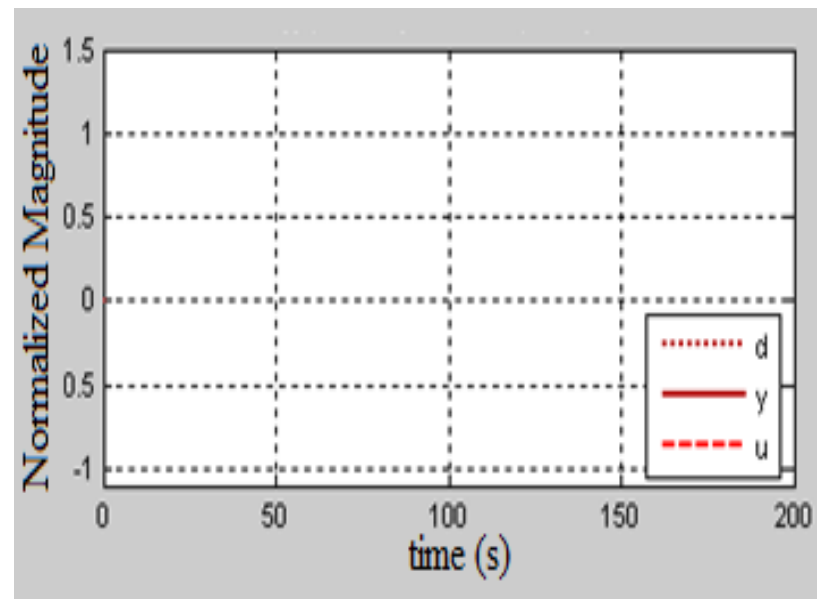

Fig. 7. Model of temperature control of heat exchanger

In Fig. 7, it appears that in general, the GUI (Graphical User Interface) consists of three components, namely:

1) Model of temperature control system,

2) Diagram transfer function, and

3) Graph feedback control results.

\section{IV.2 Model of Open Loop Control}

The next step is to model the open-loop control for controlling a heat exchanger. In this simulation, test the temperature of the heat exchanger system without a controller, as shown in Fig. 8. Shown in the graph in Fig. 8 that the response of the system is terrible, which is indicated by the signal response of the system (y) deviate from the reference signal (u).

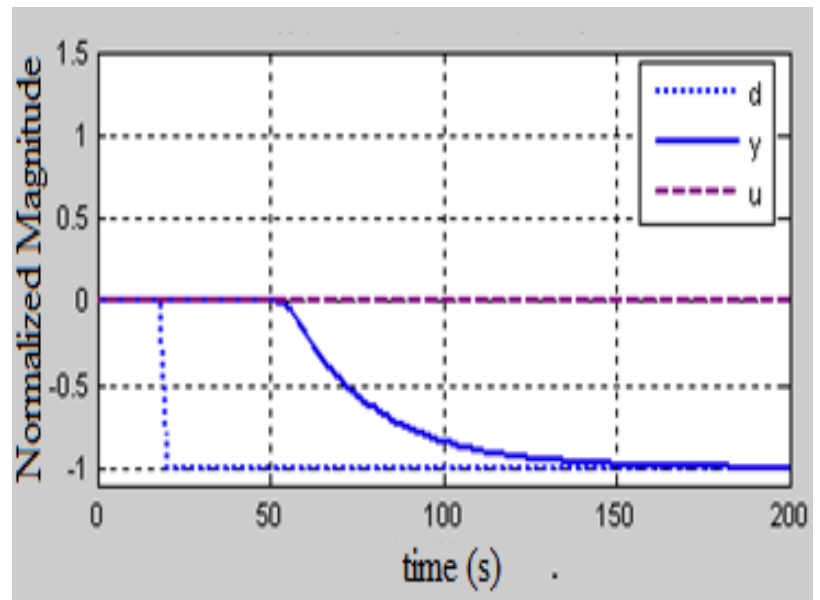

Fig. 8. Model system without controlling the temperature of a heat exchanger

\section{IV.3 Model of Feedforward Control}

The next step is to model the feedforward control for controlling a heat exchanger. In this simulation, testing of temperature in the heat exchanger system with feedforward controller types is done, as shown in Fig. 9. As can be shown in the graph in Fig. 9 shows that the response system is already delivering results that are slightly better than without a controller. The controller performance is characterized by a system response signal (u) already approaching the reference signal (y), which takes 45 seconds to get up to the magnitude of the desired temperature (i.e., 1), and finally achieved his 100th sec.

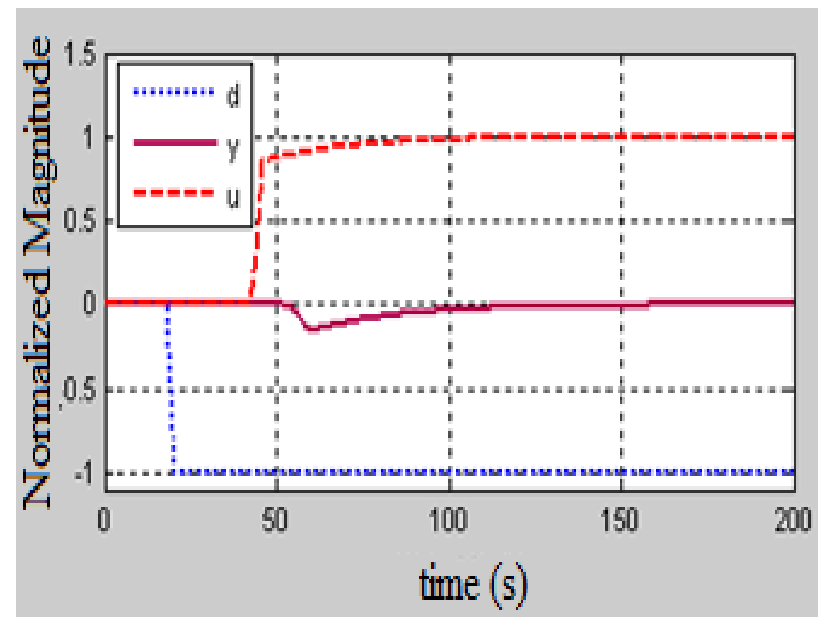

Fig. 9. Model temperature of heat exchanger system with a feedforward controller

\section{IV.4 Model of Feedback Control}

The next step is to model the feedback control for controlling a heat exchanger. In this simulation, testing of temperature in the heat exchanger system to control what type of feedback was done, as shown in Fig. 10. As can be seen in the graph in Fig. 10, the feedback system is already delivering results that are slightly better than without controllers, although relatively worse than feedforward controllers. This result is indicated by the signal response of the system $(\mathrm{u})$ is approaching the reference signal (y), which takes 55 seconds to get up to the magnitude of the desired temperature (i.e., 1). Furthermore, oscillation occurs until the second-to-150 to reach temperature stability. In the application of this control overshoot as high as $20 \%$ of the magnitude of the expected temperatures, although only occur in a relatively short period of 25 seconds to lead a stable condition. Response result this type of feedback control is relatively slow compared to the response of the feedforward control since feedback control work that always has to evaluate every previous output in the loop so computationally relatively more extended than the 
feedforward controller.

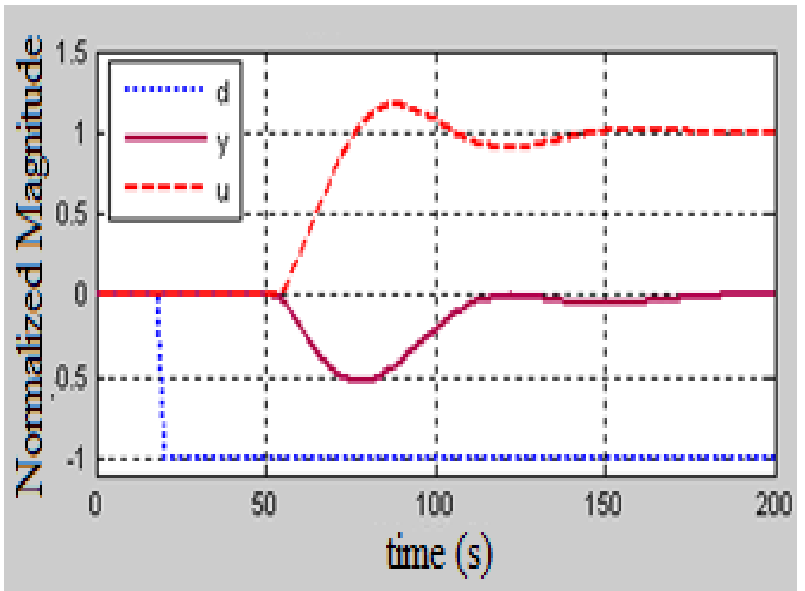

Fig. 10. Model of heat exchanger temperature system with a feedback controller

\section{IV.5 Model of Feedback and Feedforward Controls}

In this simulation, testing of temperature control in the heat exchanger system with combined type feedforward control and feedback is shown in Fig. 11. As shown in the graph of Fig. 11, it can be seen that the feedback system is already delivering results that are slightly better than the results with previous controllers. This result is indicated by the signal response of the system (u) is approaching the reference signal (y), which takes 45 seconds to get up to the magnitude of the desired temperature (i.e., 1). Furthermore, oscillation occurs until the secondto-120 to reach temperature stability at the desired magnitude is 1 .

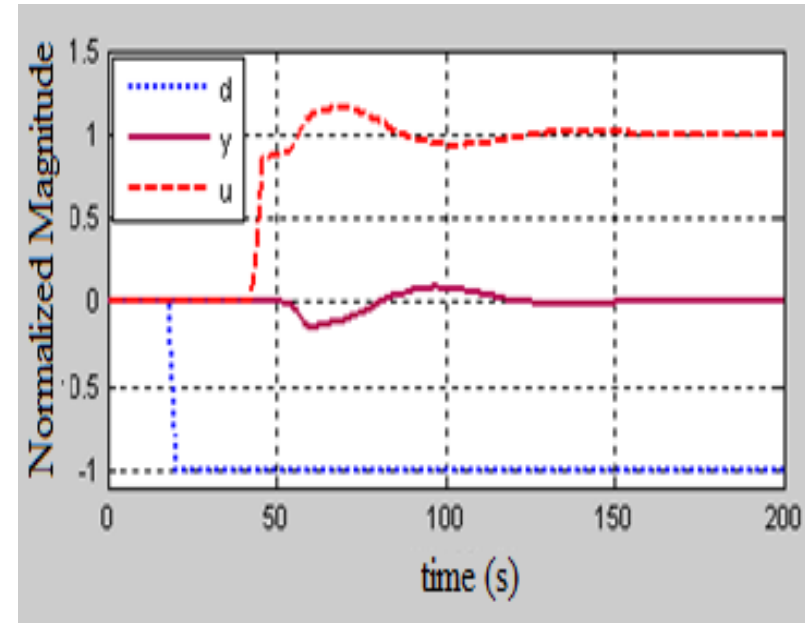

Fig. 11. Model of temperature heat exchanger system with a combination of a feedforward and a feedback controllers

In the application of this control of overshoot as high as $20 \%$ of the magnitude of the expected temperatures, although only occur in a relatively short period of 20 seconds to lead a stable condition. Response results combined feedforward and feedback control is relatively fast compared to the response of feedback control, because the work is not purely feedback controllers always have to evaluate each of the previous output in the loop. Thus the computation required is relatively shorter than the feedback controller

\section{Conclusion}

In this study conducted a simulation test system temperature in the heat exchanger with the type of feedforward controllers control the results obtained is relatively better compared with feedback control, especially in the speed of response to the situation stable. This response is due to the feedforward control requires computational load is relatively small compared with the feedback control.

In the simulation with a combined feedforward and feedback control, found that the system response is already giving results that are slightly better than results with feedforward control and feedback control. This result is evident from the 45 seconds it takes to rise to the magnitude of the desired temperature. The next time of oscillating was relatively minor and lasted for a short time to get to a state of stability, which is 20 seconds.

\section{References}

[1] Y.B. Khare, Y. Singh, "PID Control of Heat Exchanger System", International Journal of Computer Application (0975-8887), vol. 8, no. 6, October 2010.

[2] K. Erenturk, "Fractional-Order PI A. D J.I and Active Disturbance Rejection Control of Nonlinear Two-mass Drive System", IEEE Trans. Ind. Electron, vol. 60, no. 9, pp. 3806-3813, 2013.

[3] J.S. Wang, C.S.G. Lee, (2002), "Self-Adaptive Neuro-Fuzzy Inference Systems for Classification Applications", IEEE Trans. on Fuzzy Systems, 10, 6, Dec, 2002.

[4] J.S.R. Jang, (1993), "ANFIS: Adaptive-Networkbased Fuzzy Inference System", IEEE Trans. Syst., Man, Cybern., 23, 665-685, June 1993.

[5] M. Pandey, K. Ramkumar, V. Alagesan, "Design of Fuzzy Logic Controller for a Cross Flow Shell and Tube Heat-Exchanger", IEEE, Mar 2012.

[6] L.L. Ojeda, A. Chasse, R. Goussault, (2017), "Fuel consumption prediction for heavy-duty vehicles using digital maps," 2017 IEEE 20th International Conference on Intelligent Transportation Systems (ITSC), Yokohama, Japan, 16-19 Oct. 2017.

[7] R. Syahputra, (2012), "Fuzzy Multi-Objective Approach for the Improvement of Distribution 
Network Efficiency by Considering DG', IJCSIT, Vol. 4, No. 2, pp. 57-68.

[8] H. Yang, H. Rakha, M.V. Ala, (2017), "EcoCooperative Adaptive Cruise Control at Signalized Intersections Considering Queue Effects," IEEE Transactions on Intelligent Transportation Systems, Vol. 18, No. 6, June 2017, pp. 1575 - 1585.

[9] Syahputra, R., Soesanti, I. (2015). Power System Stabilizer model based on Fuzzy-PSO for improving power system stability. 2015 International Conference on Advanced Mechatronics, Intelligent Manufacture, and Industrial Automation (ICAMIMIA), Surabaya, 15-17 Oct. 2015 pp. 121 126.

[10] N. Kanagaraj, M. Al-Dhaifalla, K. S. Nisar, "Design of intelligent fuzzy fractional-order PID controller for pressure control application", 2017 International Conference on Intelligent Computing Instrumentation and Control Technologies (ICICICT), pp. 525-530, 2017.

[11]I. Petráš, "Tuning and implementation methods for fractional-order controllers", Fractional Calculus and Applied Analysis, vol. 15, no. 2, pp. 282-303, 2012.

[12] A. Vasickaninova, M. Bakosova, A. Meszaros, J. Klemes, "Neural Network Predictive Control ofa Heat Exchanger", Chemical Engineering Transactions, vol. 21, 2010.

[13] K.R. Das, D. Das, J. Das, "Optimal Tuning of PID controller using GWO Algorithm for speed control in DC Motor", IEEE International conference on soft computing techniques and implementations, 2015.

[14] A.A.M. El-Gaafary, Y.S. Mohamed, A.M. Hemeida, Al-Attar A. Mohamed, "Grey Wolf optimization for Multi input Multi output system", university journal of Communication and Network, 2015.

[15] S. Padhee, "Controller Design for temperature control of Heat Exchanger System: Simulation Studies", WSEAS Transactions on Systems and Control, vol. 9, 2014.

[16]P. Rastogi, S. Chatterji, D.S. Karanjkar, "Performance analysis of fractional-order controller for $\mathrm{pH}$ neutralization process", 2012 2nd International Conference on Power Control and Embedded Systems, vol. 2, pp. 1-6, 2012.

[17]M. Vahedpour, A.R. Noei, H.A. Kholerdi, "Comparison between performance of conventional fuzzy and fractional order PID controllers in practical speed control of induction motor", 2nd International Conference on Knowledge-Based Engineering and Innovation (KBEI), pp. 912-916, Nov 2015.

\section{Authors' information}

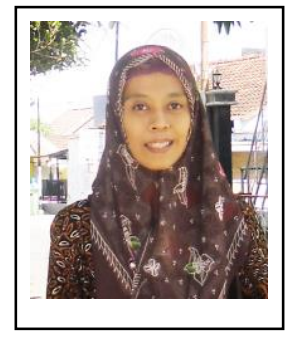

Indah Soesanti was born on June 15, 1974. She received both M.Eng. and Ph.D. degrees from Department of Electrical Engineering, Gadjah Mada University, Yogyakarta, Indonesia in 2001 and 2011, respectively.

Dr. Indah Soesanti is a Lecturer in the Department of Electrical Engineering and Information Technology, Faculty of Engineering, Universitas Gadjah Mada, Indonesia. Her research interests are in signal processing, image processing, control system, ICT-based system, optimization, artificial intelligence in signal processing pattern classification, and artificial intelligence in control system.

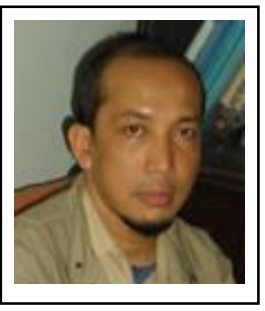

Ramadoni Syahputra received B.Sc. degree from Institut Teknologi Medan in 1998, M.Eng. degree from Department of Electrical Engineering, Universitas Gadjah Mada, Yogyakarta, Indonesia in 2002, and Ph.D. degree at the Department of Electrical Engineering, Faculty of Industrial Technology, Institut Teknologi Sepuluh Nopember,

Surabaya, Indonesia in 2015.

Dr. Ramadoni Syahputra is a Lecturer in Department of Electrical Engineering, Faculty of Engineering, Universitas Muhammadiyah Yogyakarta, Indonesia. His research interests are in computational of power system, artificial intelligence in power system, power system control, the application of fuzzy logic in power system, optimization, distributed energy resources, and renewable energy. 